\title{
Two new and one newly recorded species of Corinnidae and Liocranidae from Taiwan (Arachnida: Araneae)
}

\author{
I-Min Tso $^{1 *}$, Ming-Sheng Zhu², Jun-Xia Zhang ${ }^{2} \&$ Feng Zhang ${ }^{2}$ \\ ${ }^{1}$ Department of Life Science, Tunghai University, Taichung 407, Taiwan \\ Center for Tropical Ecology and Biodiversity, Tunghai University, Taichung 407, Taiwan \\ ${ }^{2}$ College of Life Sciences, Hebei University, Baoding 071002, China \\ *Correspondence,E-mail: spider@thu.edu.tw
}

\begin{abstract}
Three species of the families Corinnidae and Liocranidae from Taiwan are described and illustrated. Among them, the corinnid species Oedignatha scrobiculata Thorell 1881 is newly recorded from Taiwan, and two species are new to science and are named Orthobula spiniformis (Corinnidae) and Sphingius pingtung (Liocranidae).
\end{abstract}

Key words - Araneae, Corinnidae, Liocranidae, new species, new record, Taiwan

\section{Introduction}

Members of the families Corinnidae and Liocranidae are small to medium-sized, and free-living ground spiders inhabiting forest litter, with many species having the abdomen covered with dorsal and ventral scuta only in male or both in male and female. Up to the present, 900 species of 75 genera in Corinnidae and 169 species of 31 genera in Liocranidae have been recorded all over the world (Platnick 2004).

Formerly, both Corinnidae and Liocranidae were included in the Clubionidae, but now most scholars incline to treat them as independent families. However, some genera of the two families have undergone frequent transfers, and as mentioned by Deeleman-Reinhold (2001), no convincing synapomorphies have been found to define and unite all corinnids or liocranids, and worldwide classification is desiderated for these groups.

Totally three species (two genera) of Corinnidae (Phrurolithus claripes (Dönitz \& Strand 1906), P. taiwanicus Hayashi \& Yoshida 1993, Utivarachna taiwanica (Hayashi \& Yoshida 1993)) and two species (two genera) of Liocranidae (Otacilia lynx (Kamura 1994), Itatsina praticola (Bösenberg \& Strand 1906)) have been reported from Taiwan (Chen 1996; Platnick 2004). In this paper, one corinnid species new to this fauna: Oedignatha scrobiculata Thorell 1881, and two new species under the names of Orthobula spiniformis (Corinnidae) and Sphingius pingtung (Liocranidae) are described and illustrated.

\section{Materials and Methods}

All specimens used in this study including the type specimens are deposited in National Museum of Natural Science,
Taichung, Taiwan (NMNS). All measurements given are in $\mathrm{mm}$. Palp measurements are shown as total length (femur, patella, tibia, tarsus). Leg measurements are shown as total length (femur, patella and tibia, metatarsus, tarsus). Abbreviations used in this study are as follows: AME, anterior median eye; ALE, anterior lateral eye; PME, posterior median eye; PLE, posterior lateral eye; MOA, median ocular area.

\section{Oedignatha Thorell 1881}

Oedignatha Thorell 1881, p. 209; Deeleman-Reinhold 2001, p. 261.

Type species. Oedignatha scrobiculata Thorell 1881, by original designation.

Diagnosis. Distinguished from all other corinnids by the presence of a brush of dark hair close to the median base of the posterior lateral spinnerets in both sexes, and a conical hump on clypeus in front of AME. Embolus of male palp thread-like, conductor sclerotized, and tegular apophysis lanceolate and membranous. Epigynum usually with a posterior window membranous area, connecting duct short or absent (Deeleman-Reinhold 2001).

Remarks. Thirty four species have been reported in the world, which are mainly distributed in the Oriental region, from the Seychelles and Sri Lanka to the Philippines, eastward to New Guinea and Samoa. Only one species has been recorded from China (Oedignatha platnicki Song \& Zhu 1998, Hong Kong) (Platnick 2004). 
Oedignatha scrobiculata Thorell 1881

(new record from Taiwan)

(Figs. 1-3)

Oedignatha scrobiculata Thorell 1881, p. 209; DeelemanReinhold 2001, p. 267, figs. 348-356.

Oedignatha decorata Simon 1897a, p. 13.

Phrurolithus ulopatulisus Barrion \& Litsinger 1995, p. 174, figs. 100a-i, 101a-e.

Diagnosis. This species is similar to Oedignatha jocquei Deeleman-Reinhold 2001 (Deeleman-Reinhold 2001: 268, figs. 357-361), but can be distinguished from the latter by: ventral projection of tibial apophysis of male palp thumblike, retrolateral projection bifid, tegular apophysis narrow and clawlike (Figs. 2-3); spermatheca simple and oval.

Male. Total length 4.77: cephalothorax 2.30 long, 1.53 wide; abdomen 2.61 long, 1.44 wide. Carapace black, with numerous round punctuations (Fig. 1). Both eye rows procurved. AME larger than other eyes. Sternum covered with spaced conical elevations. Abdomen blackish brown, dorsum with 3 pairs of browny yellow spots at posterior half part and a few dark stripes. Abdomen with dorsal scutum, and ventral epigastric and postgenital scuta. Leg formula: 1 42 3. Tibial apophysis of palp with a thumb-shaped ventral projection and a bifid retrolateral projection, embolus long and filiform, conductor massive, tegular apophysis clawlike (Figs. 2-3).

Female. See descriptions of Deeleman-Reinhold (2001, p. 267, figs. 355-356).

Material examined. 1 male, Keng-Ting National Park, Pingtung County, Taiwan, March 2000, collected by Y. L. Hsieh (NMNS-THU-Ar-01-0196).

Distribution. Taiwan (Pingtung County), India to Philippines.

\section{Orthobula Simon 1897}

Orthobula Simon 1897b, p. 152; Deeleman-Reinhold 2001, p. 431.

Type species. Orthobula impressa Simon 1897, by original designation.

Diagnosis. Distinct from other corinnids by the expanded and lightly sclerotized tegulum of male palp, bulb simple, lacking additional apophysis. Thoracic groove reduced, femora without spines. Epigynum with a pair of rodshaped spermathecae near the epigastric fold, and a pair of membranous sacs attached to the connecting duct, and
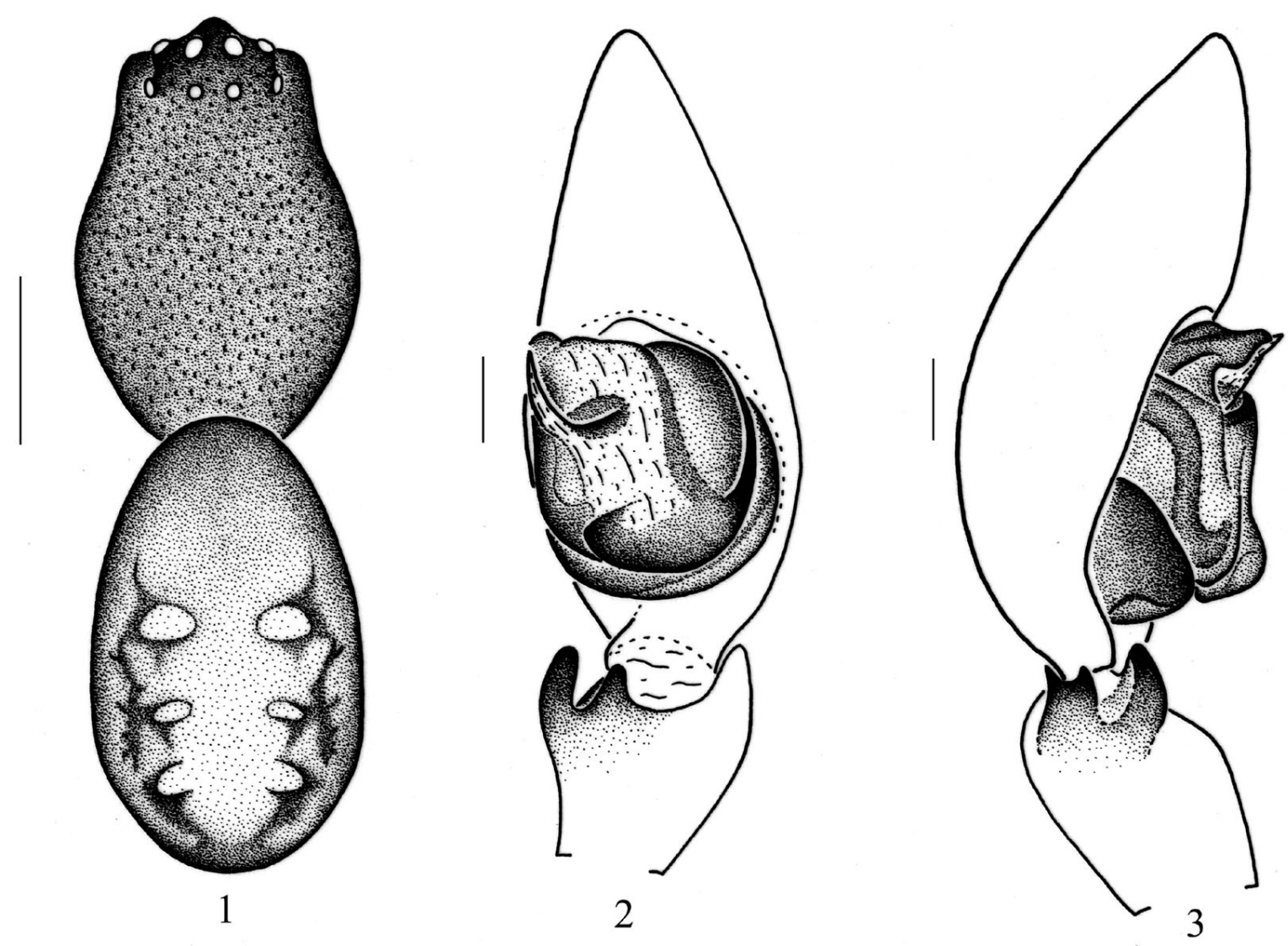

Figs. 1-3. Oedignatha scrobiculata Thorell 1881. - 1, Male, dorsal view. 2, right male palp, ventral view. 3, same, retrolateral view. (Based on a male from Keng-Ting National Park, Taiwan. Scales for Fig. 1, $1.0 \mathrm{~mm}$; for Figs. 2-3, $0.1 \mathrm{~mm}$ ) 
intromittent orifice located at anterior part (DeelemanReinhold 2001).

Remarks. Totally 16 species have been recorded all over the world, mainly distributed in the boreal and tropical Asia and Africa. Up to now, five species have been reported from the mainland, and none from Taiwan (Platnick 2004).

\section{Orthobula spiniformis new species}

(Figs. 4-8)

Types. Male holotype from Keng-Ting National Park, Pingtung County $\left(22^{\circ} 36^{\prime} \mathrm{N}, 120^{\circ} 30^{\prime} \mathrm{E}\right)$, Taiwan, January 2001, collected by Y. L. Hsieh (NMNS-THU-Ar-01-0191); 5 male and 1 female paratypes from Keng-Ting National Park, Pingtung County, Taiwan, April 2000, collected by Y.
L. Hsieh (NMNS-THU-Ar-01-0187).

Etymology. The specific name is from the Latin spiniformis, and refers to the embolus of male palp spinous in ventral view.

Diagnosis. The new species resembles Orthobula yaginumai Platnick 1977 (Platnick 1977, p. 46, figs. 5-6) in the shape of bulb of male palp, but differs from the latter in distal apophysis of palpal femur small; embolus long, unbent and spine like in ventral view (Figs. 5-6). This species is also similar to Orthobula crucifera Bösenberg \& Strand 1906 (Platnick 1977, p. 45, figs. 1-4), but can be distinguished from the latter by bulb of male palp longer, embolus longer and not twisted in lateral view (Figs. 5-6); ducts of the epigynum connecting the openings with the bases of membranous sacs oval (Figs. 7-8).

Male. Total length $1.80^{-1.94}$. Holotype total length

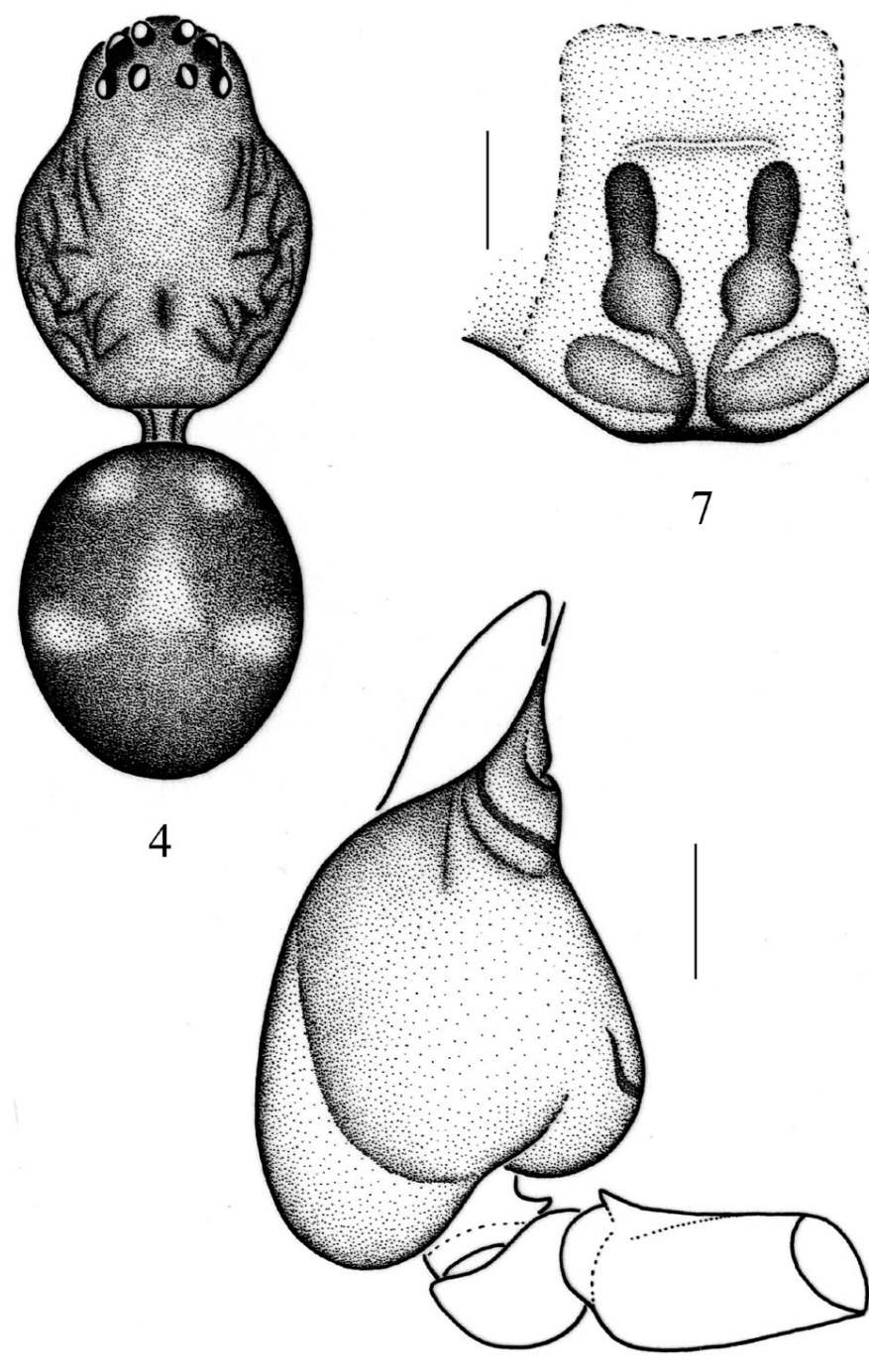

5

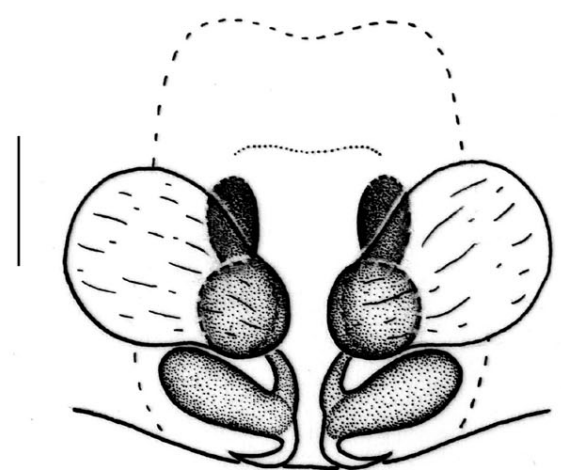

8

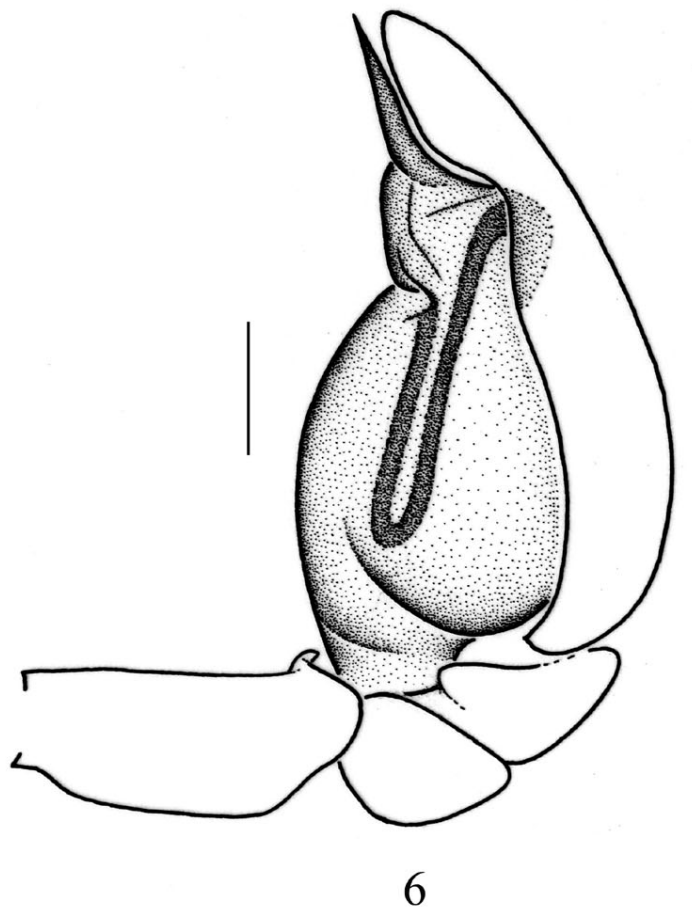

Figs. 4-8. Orthobula spiniformis new species. - 4. Male, dorsal view; 5. left male palp, ventral view; 6 . same, retrolateral view; 7. epigynum, ventral view; 8. vulva, dorsal view. (4-6: holotype male, 7-8: a female paratype from Keng-Ting National Park, Taiwan. Scales for Fig. 4, 0.5 mm; for Figs. 5-8. 3, $0.1 \mathrm{~mm}$ ) 
1.90: cephalothorax 0.95 long, 0.73 wide; abdomen 0.83 long, 0.70 wide. Carapace reddish brown, with lateral blackish brown stripes. Chelicerae yellowish brown, with 3 teeth on promargin and none on retromargin. Labium, endites and sternum reddish brown. Sternum with many punctuations. Legs yellowish brown. Tibiae I and II with 5 pairs of ventral spines, metatarsi I and II with 4 pairs of ventral spines. Abdomen covered with a scutum over the full length dorsally, and ventrally with an epigastric scutum and a partial postgenital scutum; dorsum blackish brown, with a few reddish brown patches, venter grayish brown. Anterior eye row recurved, and posterior eye row almost straight. AME-AME 0.03, AME-ALE 0.01, PME-PME 0.05, PME-PLE 0.04; AME 0.05, ALE 0.07, PME 0.08, PLE 0.08. MOA 0.17 long, front width 0.13 , back width 0.17 . Labium wider than long (0.18: 0.13). Sternum longer than wide $(0.56: 0.47)$. Measurements of palp and legs: palp $0.90(0.26,0.10,0.10$, 0.44); leg I $2.12(0.65,0.78,0.47,0.22)$, II $1.91(0.55,0.72$, $0.42,0.22)$, III $1.64(0.49,0.59,0.31,0.25)$, IV $2.24(0.60$, $0.77,0.57,0.30$ ). Leg formula: 4123 . Palpal femur with a small ventral apophysis distally, patella and tibia short; tibia with a small triangular retrolateral apophysis; bulb globose and triangular, with long and unbent embolus (Figs. 5-6).

Female. Total length 2.45: cephalothorax 1.09 long, 0.82 wide; abdomen 1.46 long, 1.04 wide. Dorsum of abdomen grayish brown, lacking dorsal scutum, with 2 pairs of yellowish brown sigilla. Other characters as in male holotype. Measurements of legs: I $2.50(0.68,0.95,0.57,0.30)$, II 2.26 $(0.68,0.83,0.48,0.27)$, III $2.00(0.59,0.70,0.44,0.27)$, IV $2.70(0.77,0.91,0.69,0.33)$. Leg formula: $4,1,2,3$. Epigynum almost quadrate; vulva with a pair of oval spermathecae posteriorly and a pair of large membranous sacs attached in the middle with its base large, round and sclerotized (Figs. 7-8).

Distribution. Taiwan (Pingtung County).

\section{Sphingius Thorell 1890}

Sphingius Thorell 1890, p. 284; Deeleman-Reinhold 2001, p. 488.

Type species. Sphingius thecatus Thorell 1890, by original designation.

Diagnosis. Species of this genus can be distinguished

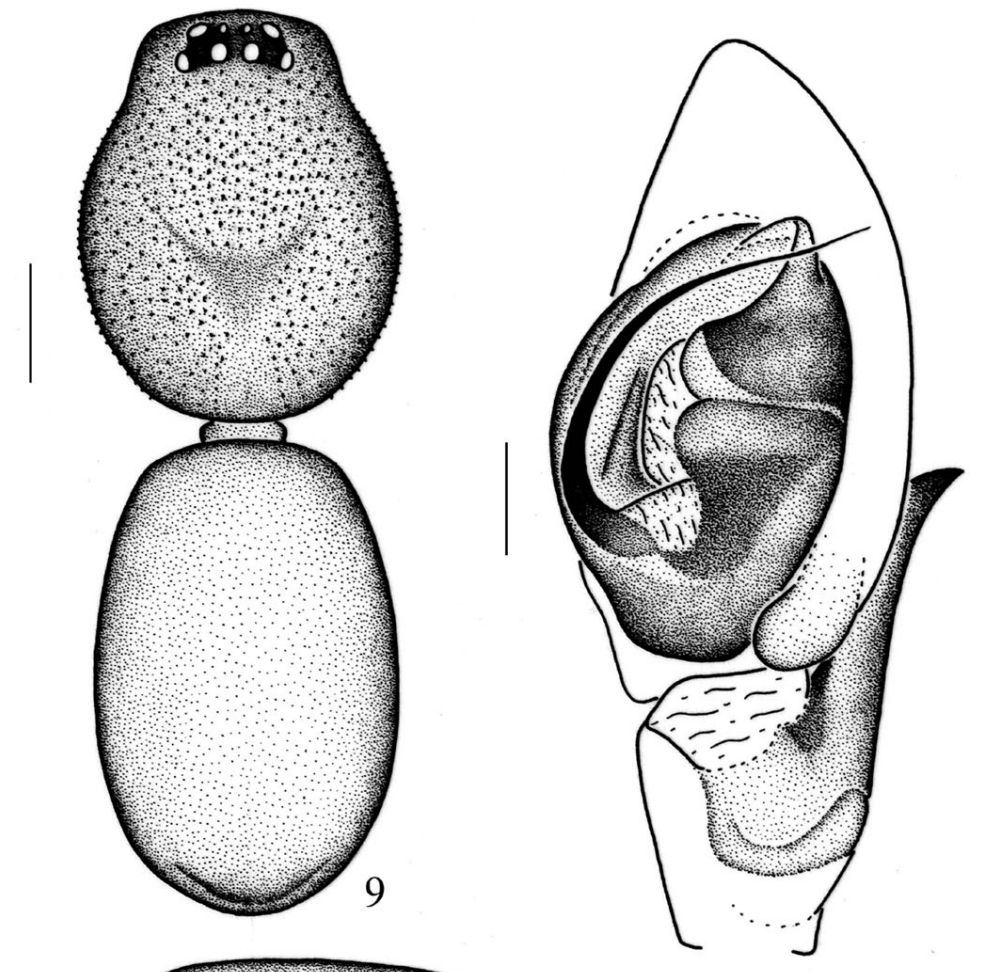

11

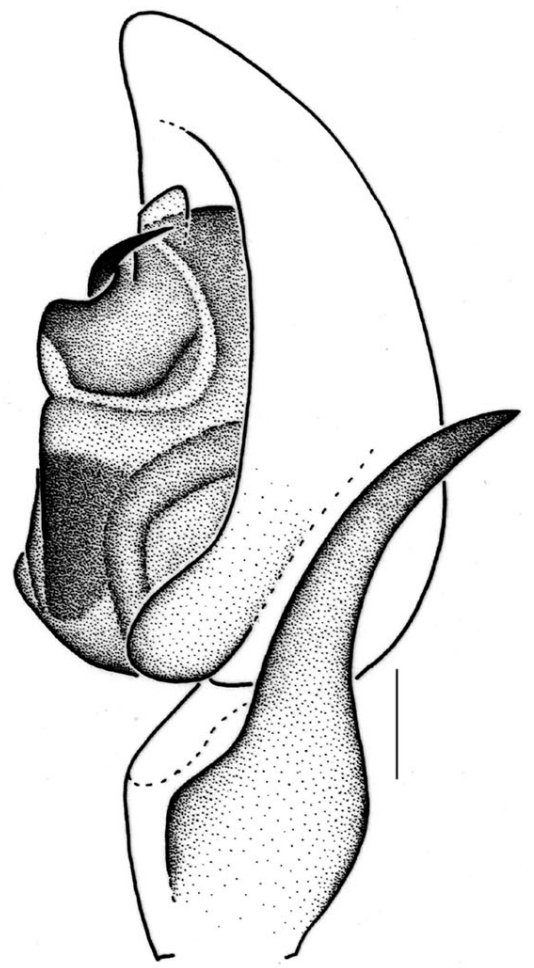

12

10

Figs. 9-12. Sphingius pingtung new species. - 9. Male, dorsal view; 10. abdomen, lateral view; 11. left male palp, ventral view; 12. same, retrolateral view. (Based on male holotype from Keng-Ting National Park, Taiwan. Scales for Figs. 9-10, 0.5 mm; for Figs. 11-12, $0.1 \mathrm{~mm})$ 
from other liocranid spiders by anterior spinnerets conical and juxtaposed, abdomen of male with entire dorsal, epigastric and postgenital scuta. In female, only the epigastric scutum present. Tibiae I and II, metatarsi I and II spineless. Embolus of male palp filiform, conductor membranous or absent, median apophysis compact. Epigynum usually with an anterior depression (Deeleman-Reinhold 2001).

Remarks. Small genus composed of 18 species distributed in the Southeast and South Asia (Platnick 2004). No species have been reported from Taiwan or mainland before.

\section{Sphingius pingtung new species} (Figs. 9-12)

Types. Male holotype from Keng-Ting National Park, Pingtung County $\left(22^{\circ} 36^{\prime} \mathrm{N}, 120^{\circ} 30^{\prime} \mathrm{E}\right)$, Taiwan, November 2000, collected by Y. L. Hsieh (NMNS-THU-Ar-01-0194).

Etymology. The specific name is a noun in apposition taken from the type locality.

Diagnosis. The new species is similar to Sphingius vivax (Thorell 1897) (Deeleman-Reinhold 2001, p. 494, figs. 840842 ) in carapace with many small granulations, but can be easily distinguished from the latter by embolus of male palp much longer, tibial apophysis large and acinaciform (Figs. 11-12). This new species also resembles $S$. scrobiculatus Thorell 1897 (Deeleman-Reinhold 2001, p. 489, 493, figs. 839 ) in male palp with a large tibial apophysis, but differs from the latter in: PME-PME smaller than 1 diameter of PME; embolus of male palp long, and tibial apophysis not beyond half of cymbium (Figs. 11-12).

Male. Holotype total length 3.69: cephalothorax 1.62 long, 1.17 wide; abdomen 2.07 long, 1.26 wide. Carapace deep reddish brown, with numerous small granulations. Chelicerae reddish brown, slightly swollen in front surface, with 4 promarginal and 2 retromarginal teeth. Labium, endites and sternum reddish brown. Sternum with many small punctuations. Legs reddish brown, with a few fine spines and hairs. Abdomen reddish brown, covered with dorsal and ventral scuta. Anterior eye row almost straight, and posterior eye row recurved. AME-AME 0.06, AMEALE 0.03, PME-PME 0.04, PME-PLE 0.04; AME 0.05, ALE 0.09, PME 0.10, PLE 0.09. MOA 0.20 long, front width 0.22 , back width 0.25 . Labium as long as wide $(0.32$ : $0.32)$. Sternum longer than wide (1.00: 0.88). Measurements of palp and legs: palp $1.75(0.68,0.31,0.20,0.56)$; leg I $4.56(1.33,1.63,0.85,0.75)$, II $4.08(1.19,1.41,0.80,0.68)$, III femur 1.16 (distal four segments missing in both legs III), IV $5.28(1.39,1.73,1.33,0.83)$. Tibial apophysis of palp large and acinaciform, embolus long and flagelliform.

Female. Unknown.

Distribution. Taiwan (Pingtung County).

\section{References}

Barrion, A. T. \& Litsinger, J. A. 1995. Riceland Spiders of South and Southeast Asia. CAB International, Wallingford, UK, xix $+700 \mathrm{pp}$.

Bösenberg, W. \& Strand, E. 1906. Japanische Spinnen. Abh. Senckenb. Naturf. Ges., 30: 93-422, pls. 3-16.

Chen, S. H. 1996. A checklist of spiders in Taiwan. Ann. Taiwan Mus., 39: 123-156.

Deeleman-Reinhold, C. L. 2001. Forest Spiders of South East Asia: with a Revision of the Sac and Ground Spiders (Araneae: Clubionidae, Corinnidae, Liocranidae, Gnaphosidae, Prodidomidae and Trochanterriidae [sic]) Brill, Leiden, 591 pp., 8 pls.

Platnick, N. I. 1977. On East Asian Orthobula (Araneae, Clubionidae). Acta Arachnol. Tokyo, 27: 43-47.

Platnick, N. I. 2004. The World Spider Catalog, version 4.5. American Museum of Natural History, online at http:// research.amnh.org/entomology/spider/catalog81-87/index.html

Simon, E. 1897a. Description d'arachnides nouveaux. Ann. Soc. Entomol. Belgique, 41: 8-17.

Simon, E. 1897b. Histoire Naturelle des Araignées. Paris, 2: 1192.

Song, D. X. \& Zhu, M. S. 1998. A new genus and two new species of Hong Kong spiders (Gnaphosidae, Corinnidae). J. Hebei Normal Univ. (Nat. Sci.), 22: 104-108.

Thorell, T. 1881. Studi sui Ragni Malesi e Papuani. III. Ragni de 1l'Austro Malesia e del Capo York, conservati nel Museo civico di storia naturale di Genova. Ann. Mus. Civ. Stor. Nat. Genova, 17: $1^{-}$ 727.

Thorell, T. 1890. Studi sui ragni Malesi e Papuani. IV, 1. Ann. Mus. Civ. Stor. Nat. Genova, 28: 1-419.

Received November 30, 2004 / Accepted February 7, 2005 